\title{
A tool for determining maximum sustained swimming ability of selected inland fish species in an Afrotropic ecozone
}

\author{
TL Botha'*, MP Mahloko', V Wepener ${ }^{1}$, G Howatson ${ }^{1,2}$ and NJ Smit ${ }^{1}$ \\ 'Water Research Group, Unit for Environmental Sciences and Management, Potchefstroom Campus, North West University, Private Bag X6001, \\ Potchefstroom, 2520, South Africa \\ ${ }^{2}$ Faculty of Health and Life Sciences, Northumbria University, Newcastle upon Tyne, United Kingdom
}

\begin{abstract}
Critical swimming speed $\left(U_{\text {cri) }}\right)$ predicts the maximum sustained swimming velocity that various fish species are able to sustain for prolonged periods. The objective of this study was to determine the $U_{\text {crit }}$ of Afrotropic ecozone fish, determine oxygen consumption at $U_{\text {crit }}$ and relate the resulting optimum flow requirements to effective movement through fishways under South African flow conditions. The selected fish species were Coptodon rendalli, Tilapia sparrmanii, Pseudocrenilabrus philander, Oreochromis mossambicus and Enteromius trimaculatus. $U_{\text {crit }}$ and oxygen consumption $\left(\mathrm{MO}_{2}\right)$ were measured in a swim respirometer at 5-min intervals, at increasing velocity increments of $0.5 \mathrm{~cm} \cdot \mathrm{s}^{-1}$ until volitional exhaustion. No significant differences were seen in the $U_{\text {crit }}$ values between C. rendalli, T. sparrmanii and P. philander, but all species significantly differed from O. mossambicus and E. trimaculatus, which had the highest $U_{\text {crit }}\left(17.6 \pm 1.5 \mathrm{bl} \cdot \mathrm{s}^{-1}\right.$ and $\left.18.2 \pm 2.8 \mathrm{bl} \cdot \mathrm{s}^{-1}\right)$. Size plays an important role in the swimming performance of fish, with larger fish able to sustain a greater velocity, which was specifically true for O. mossambicus in this study. Additionally, smaller fish consumed more oxygen during swimming and therefore used more energy, experiencing relative physiological strain. Based on these data, flow respirometry was shown to be a useful tool to determining prolonged swimming abilities of South African fish species, and can help inform the structure and flow rates of culverts and fishways.
\end{abstract}

Keywords: migration barriers, fishways, critical swimming speed, oxygen consumption

\section{INTRODUCTION}

Swimming performance is measured as a principle trait that determines the survival of many fish species (Tudorache et al., 2008), and is critical to avoid predators, move between habitats and negotiate barriers (natural and man-made) to breed, feed or survive unfavourable environments (Smith and Sharman, 2013). It is fundamental to understand the sustained swimming ability of fish determined by calculating critical swimming speed (Tudorache et al., 2008).

Critical swimming speed $\left(U_{\text {crit }}\right)$ is a commonly used method to assess the maximum sustainable swimming speed for the time interval used in the test (Peake, 2008), and represents the indicative maximum aerobic performance of a fish. Moreover, $U_{\text {crit }}$ is associated with the physiological condition of the fish and is regularly used as a welfare indicator (Carbonara et al., 2012). In addition, $U_{\text {crit }}$ plays an important role in determining the water velocity in an environment that a specific species is capable of negotiating. When swim speeds exceed $U_{\text {crit }}$ for extended periods, the metabolic demand for oxygen will be greater than that supplied by cardiorespiratory systems and hence increase anaerobic metabolism and oxygen deficit, similar to that experienced during ambient hypoxia (Barbieri, 2007; Bushnell, 1984), which will cause disruptions in homeostasis.

The Afrotropic ecozone of sub-Saharan Africa readily experiences drought as well as seasons of extreme rainfall (US DOE, 2012). Aquatic systems are subject to human manipulation by the installation of structures that have the

\footnotetext{
To whom all correspondence should be addressed.

iㅛ +27 182992741 ;

e-mail:26964546@nwu.ac.za

Received 28 July 2017; accepted in revised form 9 July 2018
}

potential to impact water flow within the system and ultimately the fishes' ability to move and survive. Consequently, a key factor in the design of structures (e.g. culverts and fishways) to overcome migration barriers is to determine the fishes' swimming ability (Santos et al., 2007). Therefore, knowledge of $U_{\text {crit }}$ is important because it can illustrate the physiological capacity or 'fish fitness' of a particular species (De Peyster and Long, 1993). Importantly, these data could inform the management of water systems to determinine fish movement through these structures to improve the sustainability of inhabitant species (Bok et al., 2007).

Most of the fish species in this study use seasonal local relocation within a system in order to exploit new habitats that become available during natural cyclic variations in the river system. These include breeding reaches, which aid in genetic dispersal, as well as foraging, avoiding predators and moving away from unfavourable environmental conditions (Ross, 2015). In order to support successful migration and diversity of fish species within a system, fishways need to be designed to cater for the weakest-swimming species (Garcia de Leaniz, 2008; Pon, 2008).

According to Peake (2008), one practical application of $U_{\text {crit }}$ is related to the establishment of water velocity criteria for fishways and culverts. Most of the information available on environmental water flow for fish passage through fishways is based on European fish species (Peake, 2008). To our knowledge, there are no quantified data on critical swimming speed using African fish species, despite the fact many aquatic environments on the African continent are subjected to impoundments to provide water for human consumption, hydropower and agriculture. The knowledge of $U_{\text {crit }}$ and oxygen consumption of fish species can directly inform researchers and practitioners on the physiological capacity of fish. Determining $U_{\text {crit }}$ data for healthy fish populations will 
provide an evidence base to inform the management agencies about the performance of fish species in South Africa's aquatic environments. The aim of this study was to determine: (i) the sustained maximum swimming speed of selected indigenous fish species, and (ii) the oxygen consumption rates during the maximum sustained swimming speed.

\section{MATERIALS AND METHODS}

\section{Collection of the fish}

All experimental procedures were approved by the University Research Ethics Committee (Ethics number: NWU 00095-12-S4). Seven replicates per species were used; descriptive data for each species are presented in Table 1. All fish were bred in the aquarium (North-West University Potchefstroom Campus, Potchefstroom, North West, South Africa) and tested in a laboratory at the same location. The temperature selected for each individual species' swimming experiment was based on species-specific ranges set out in Skelton (2001).

\section{Experimental design}

The experiment was done using a $5 \mathrm{~L}$ respirometer Loligo swim chamber (Viborg, Denmark). The swim chamber was calibrated using digital particle tracking velocimetry (DPTV) from Loligo Systems (Viborg, Denmark) to ensure the water velocity measurements were accurate. Briefly, $2 \mathrm{mg}$ of green fluorescent beads were added to distilled water with a drop of detergent and then injected into the chamber and illuminated using a laser. A $3 \mathrm{~cm}$ area was marked to indicate the calibration image using a ruler. The beads were tracked using a $150 \mathrm{~Hz}$ high-speed camera (3.0 U-Eye IDS Imaging Development Systems, Obersulm, Germany) at 5-min intervals at incrementally increasing flow velocities. The DPTV software tracked the movement of the particles and the mean velocity was determined using the direction of the particles over a $3 \mathrm{~cm}$ area. The resultant calculation allowed for the determination of the appropriate flow velocity for each individual fish (determined by a multiple of each fish's body length).

The Autoresp programme (Loligo systems, Denmark) general settings were set up for Channel 1 , ambient oxygen $\mathrm{N}^{\circ} 1$ and ambient temperature $\mathrm{N}^{\circ} 1$. Auto-configure settings were set to manual set up and the temperature and oxygen probes were calibrated using a two-point calibration method according to Loligo AutoResp User manual (version 2.2.0). Oxygen data capture was set to calculate oxygen consumption in $\mathrm{mgO}_{2} \cdot \mathrm{L}^{-1}$.

TABLE 1

Size (length and mass) of the fish species, $\boldsymbol{U}_{\text {crit }}$ mean and standard deviation

\begin{tabular}{|l|c|c|c|}
\hline Species & Length $(\mathbf{c m})$ & Mass $(\mathbf{g})$ & $U_{\text {crit }}\left(\mathbf{b l} \cdot \mathbf{s}^{-1}\right)$ \\
\hline Tilapia sparrmanii & $12.0-13.0$ & $29.9-39.4$ & $12.46 \pm 3.06$ \\
\hline Coptodon rendalli & $10.0-13.0$ & $14.6-33.2$ & $12.31 \pm 1.20$ \\
\hline $\begin{array}{l}\text { Pseudocranilabrus } \\
\text { philander }\end{array}$ & $5.0-6.0$ & $1.1-3.85$ & $11.73 \pm 0.98$ \\
\hline $\begin{array}{l}\text { Oreochromis } \\
\text { mossambicus }\end{array}$ & $10.0-13.0$ & $12.0-31.6$ & $17.61 \pm 1.47$ \\
\hline $\begin{array}{l}\text { Enteromius } \\
\text { trimaculatus }\end{array}$ & $8.0-9.0$ & $5.65-11.0$ & $18.17 \pm 2.82$ \\
\hline
\end{tabular}

The chambers were flushed with oxygen-rich water until oxygen saturation recovered to above $5 \mathrm{mg} \cdot \mathrm{L}^{-1}$ between experiments, so that swimming performance was not affected. To ensure that a closed system was used the intermittent respirometry settings were set to flush for $0 \mathrm{~s}$, wait for $1 \mathrm{~s}$ and then measure for $300 \mathrm{~s}$. The total length $(\mathrm{cm})$ and mass $(\mathrm{g})$ of each fish were recorded prior to starting each experiment.

A hard water was prepared in the lab by adding $10.80 \mathrm{~g}$ of magnesium sulphate, $17.28 \mathrm{~g}$ sodium hydrogen carbonate, $0.72 \mathrm{~g}$ of potassium chloride and $10.80 \mathrm{~g}$ of calcium sulphate to $25 \mathrm{~L}$ of distilled water. The medium was oxygenated for $24 \mathrm{~h}$ using an air diffuser stone until a minimum of $5 \mathrm{mg} \cdot \mathrm{L}^{-1}$ oxygen concentration was achieved. The chamber was flushed between experiments to circulate oxygen into the chamber and to remove wastes.

\section{Swimming performance, oxygen consumption and calculation of critical swimming speed}

Fish were placed in the respirometer and swam at a start velocity of 2 body lengths per second $\left(\mathrm{bl} \cdot \mathrm{s}^{-1}\right)$. The water velocity was increased at increments of $0.5 \mathrm{bl} \cdot \mathrm{s}^{-1}$ at 5 -min intervals, as used by Plaut (2000). The velocity was increased until the fish could not maintain position within the chamber. The loss of position indicated fatigue and the experiments were terminated when the fish came in contact with the opposite end of the respirometer for a period of $3 \mathrm{~s}$. The critical swimming speed was calculated using the equation for $U_{\text {crit }}$ as indicated by Plaut (2001).

$$
U_{\text {crit }}=U_{\mathrm{i}}+\left[U_{\mathrm{ii}}\left(T_{\mathrm{i}} / T_{\mathrm{ii}}\right)\right]
$$

where: $U_{\mathrm{i}}$ is highest velocity maintained for the whole interval $\left(\mathrm{cm} \cdot \mathrm{s}^{-1}\right), U_{\mathrm{ii}}$ is velocity increment $\left(\mathrm{cm} \cdot \mathrm{s}^{-1}\right), T_{\mathrm{i}}$ is time elapsed at fatigue velocity ( $\mathrm{min}$ ), and $T_{\mathrm{ii}}$ is prescribed interval time (min) (Plaut, 2001).

At the end of the experiment, the decrease in oxygen consumption values of each individual were averaged over a 5-min phase and the linear regression was calculated. The slope was used to determine the absolute and relative oxygen content used by the fish during each time period based on mass (Svendsen et al., 2016).

\section{Statistics}

Significance between the various datasets $\left(U_{\text {crit }}\right.$ and the $\left.\mathrm{MO}_{2}\right)$ was determined by using one-way ANOVA using Tukey's multiple comparison test. Significance was measured as $p<0.05$. All data are presented as individual scatter points and the mean is displayed on the graph. The water velocity $\left(\mathrm{cm} \cdot \mathrm{s}^{-1}\right)$ and $U_{\text {crit }}$ dependent on the length of the fish $(\mathrm{cm})$ was plotted using GraphPad Prism (Version 6, GraphPad Software, Inc. USA), where a non-linear regression curve fit was performed using the following power equation $\left(y=a x^{b}\right)$. The $R^{2}$ and $p$ values were used to indicate a relationship between length and water velocity.

\section{RESULTS}

The descriptive data for each fish species are presented in Table 1. The smallest fish measured $5.0 \mathrm{~cm}$ in total length while the largest measured $13.0 \mathrm{~cm}$; the smallest $P$. philander had a mass of $1.10 \mathrm{~g}$ while the largest fish, T. sparrmanii, had a mass of 39.0 g. Oreochromis mossambicus and E. trimaculatus showed the highest $U_{\text {crit }}$ values $\left(17.61 \pm 1.47 \mathrm{bl} \cdot \mathrm{s}^{-1}\right.$ and $\left.18.17 \pm 2.82 \mathrm{bl} \cdot \mathrm{s}^{-1}\right)$ 
and differed significantly from all other species but not from one another (Fig. 1). The $U_{\text {crit }}$ of T. sparrmanii and P. philander had a coefficient of variance within species of 22 to $24 \%$ while all other species ranged from 9 to $16 \%$.

Pseudocranilabrus philander displayed a higher oxygen consumption rate $\left(4.81 \mathrm{mg} \cdot \mathrm{O}_{2} \cdot \mathrm{kg}^{-1} \cdot \mathrm{min}^{-1}\right)$ but there were no significant differences $(p>0.05)$ between this species and the other species. Pseudocranilabrus philander had one distinct outlier where the mass of the fish (1.1 g) was much lower than that of the other fish (Fig. 2).

The larger the fish, the higher the velocity they were able to manage before approaching critical swimming speed (Fig. 3). Two groupings were seen, where fish less than $8.0 \mathrm{~cm}$ could only withstand a velocity below $90.0 \mathrm{~cm} \cdot \mathrm{s}^{-1}$, while fish above $8.0 \mathrm{~cm}$ could manage in a velocity of up to $230.0 \mathrm{~cm} \cdot \mathrm{s}^{-1}$. Statistical analysis revealed that $O$. mossambicus demonstrated a significant ( $p=0.0062$ ) relationship between water velocity and fish length while all other species did not.

\section{DISCUSSION}

All selected fish species naturally occur in habitats with still to slow-flowing water, preferably surrounded by vegetation, and T. sparrmanii and C. rendalli, as well as P. philander, are well adapted to these environments (Skelton, 2001). According to Kleynhans (2003), all selected fish species have a moderate to very high preference for slow-deep and slow-shallow $\left(<0.3 \mathrm{~m} \cdot \mathrm{s}^{-1}\right)$ habitats. Only E. trimaculatus has a moderate preference for fast-deep and fast-shallow $\left(>0.3 \mathrm{~m} \cdot \mathrm{s}^{-1}\right)$ habitats. Oreochromis mossambicus showed a linear relationship between size and $U_{\text {crit }}$ and E. trimaculatus are relatively hardy fish which are able to adapt to several habitats (Skelton, 1993). The results of this study are consistent with sustainable swimming speeds within the family Cichlidae (Fisher and Wilson, 2004). The latter two species showed a higher tolerance to increased water velocities compared to the other fish species and no significant differences were observed between the $U_{\text {crit }}$ values of the T. sparrmanii, C. rendalli and $P$. philander.

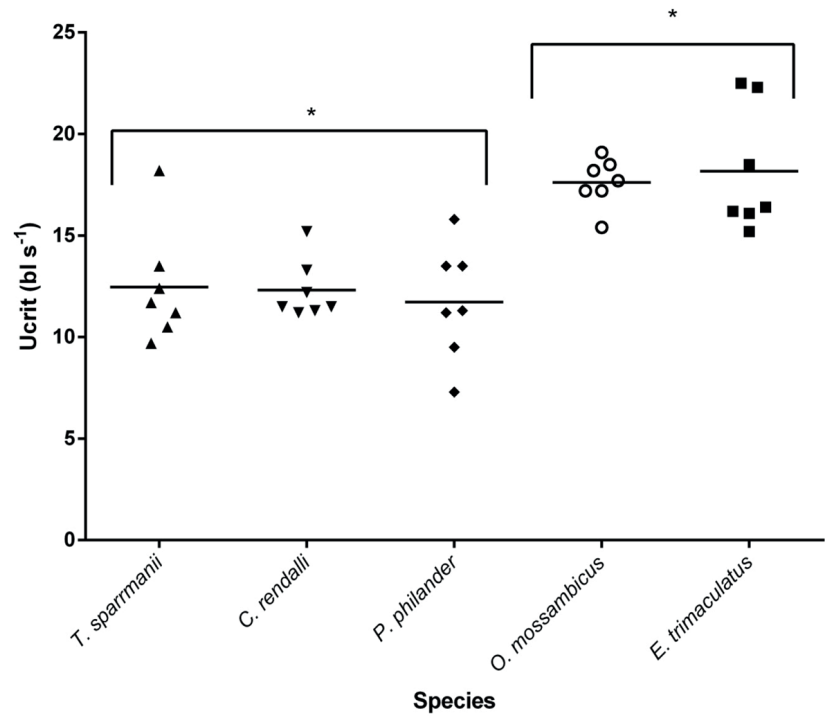

Figure 1

The critical swimming speed $\left(b / \cdot s^{-1}\right)$ of the selected species, where the mean is displayed in the centre of the scatter plot of $U_{\text {crit }}$ values within species. The asterix $(*)$ indicates significance where $p<0.05$ obtained using Tukey's multiple comparison test.
Fisher and Hogan (2007) suggested that total length be utilized to show differences in swimming performance between taxonomic groups. Migrating young fish species are found to have slower swimming velocities as a result of their shorter length (Fuiman and Webb, 1988; Plaut and Gordon 1994; Plaut, 2001; Castro-Santos, 2005). Pseudocrenilabrus philander had the shortest length of all fish species and were also the species which was only able to maintain a sustained swimming speed below $90 \mathrm{~cm} \cdot \mathrm{s}^{-1}$, similar to flows achieved by Atlantic salmon and Brown trout (Peake, 2008). The burst speed a fish uses is used for a short duration in time in order to navigate rapid increases in flow, as seen through a V slot, while the prolonged swimming speed as tested within this study gives an indication of speeds achievable within resting pools. Pseudocrenilabrus philander in this study had a $U_{\text {crit }}$ comparable

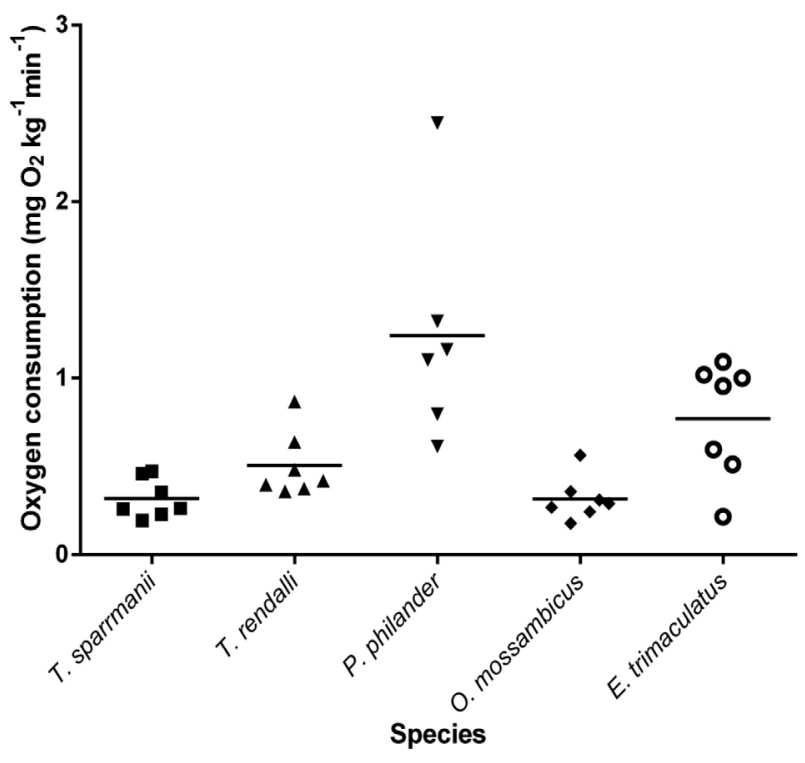

Figure 2

The oxygen consumption $\left(\mathrm{mg} \cdot \mathrm{O}_{2} \cdot \mathrm{kg}^{-1} \cdot \mathrm{min}^{-1}\right)$ of the selected species where the mean is displayed in the centre of the scatter plot.

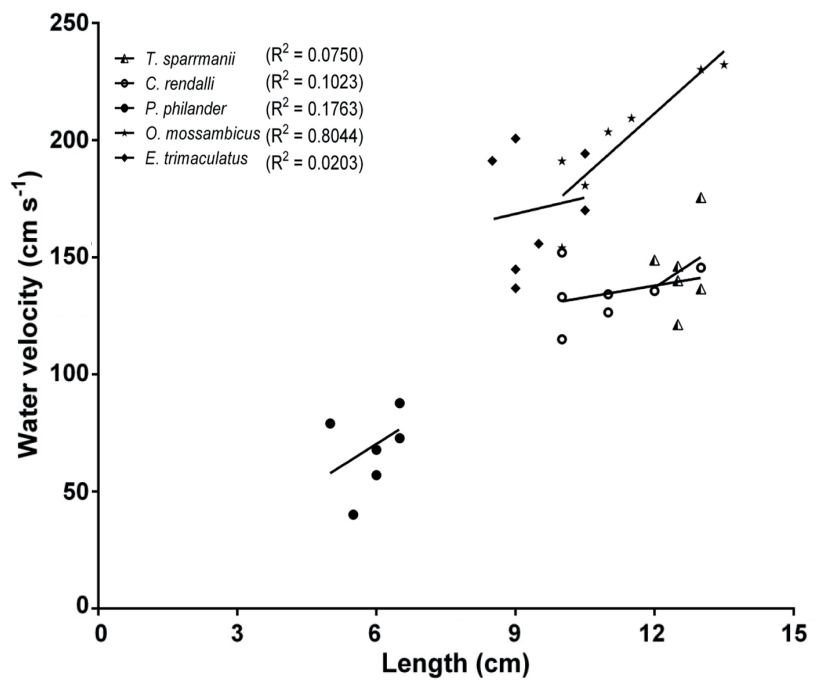

Figure 3

The relationship between water velocity $\left(\mathrm{cm} \cdot \mathrm{s}^{-1}\right)$ at critical swimming speed and the length $(\mathrm{cm})$ per species with $R^{2}$ of the non-linear regression indicated on the graph. 
to Pseudocrenilabrus multicolor victoriae $\left(30-46 \mathrm{~cm} \cdot \mathrm{s}^{-1}\right)$ as found by Gotanda et al. (2012). The other fish species, which were larger in size, had higher swimming durations giving higher $T_{\mathrm{i}}$ values (lowest $T_{\mathrm{i}} 67 \mathrm{~min}$ and the highest $T_{\mathrm{i}} 150 \mathrm{~min}$ ); an individual fish therefore swam for $2 \mathrm{~h} 30 \mathrm{~min}$. Although relative locomotor velocity in $\mathrm{bl} \cdot \mathrm{s}^{-1}$ is inversely proportional to body size (Ojanguren and Brana, 2003; Bellwood and Fisher, 2001), the species used in this study showed that prolonged swimming velocity in $\mathrm{bl} \cdot \mathrm{s}^{-1}$ is directly proportional to body size, as the larger fish species yielded higher $U_{\text {crit }}$ values than the smaller species.

Compared to other species, which also have a preference for slow water, $P$. philander had a higher mean oxygen consumption rate. Due to the size of this species, when individuals swam at swimming speeds approaching $U_{\text {crit' }}$ their metabolic demand for oxygen was more than what could be supplied by their ventilatory and circulatory systems, resulting in an oxygen debt and increased energy expenditure, a phenomenon also seen in other smaller species, such as Danio rerio (Bushnell, 1989; Videler, 1993; Ohlberger et al., 2007). The differences in rate of oxygen consumption between species can be attributed to smaller fish (1.1-3.85 g) having limited energy reserves when compared to larger fish (Fisher and Wilson, 2004), since metabolic rate is associated with body mass by an allometric relationship (Ohlberger et al., 2007). Compared to the other larger fish, which had a lowest mass of $5.65 \mathrm{~g}$, size has an effect on metabolic rate. However, no significant differences were found between the $\mathrm{MO}_{2}$ rates of O. mossambicus, E. trimaculatus, P. philander, T. sparrmanii and $C$. rendalli, with all of these displaying extremely low rates of oxygen consumption, thus indicating very good swimming endurance and little physiological stress as they approached critical swimming speed.

Two distinct swimming behaviours were observed during swimming trials; active swimming and active avoidance. The active swimming behaviour was observed in an experiment done on D. rerio by Plaut and Gordon (1994), where the species were directed downstream at lower velocities and swam with their heads directed upstream as the water velocity was increased, the fish would drift in low velocities but were quick to maintain position in the water within the middle of the chamber even when flows were increased. Enteromius trimaculatus were efficient swimmers and they displayed similar swimming behaviour to $D$. rerio. Both these species indicate high tolerance to increased flows and displayed good swimming ability. Danio rerio adapts by using bursts of energy to maintain position as water velocity increases and E. trimaculatus followed the same pattern and was able to maintain this swimming ability across all velocities, even up to $180 \mathrm{~cm} \cdot \mathrm{s}^{-1}$. However, they do not fatigue gradually, but rather terminate swimming activity abruptly and become inanimate at the back of the chamber.

Although O. mossambicus individuals displayed high swimming speeds, they were able to resist swimming within the respirometer and the test subject fish had to be replaced regularly. Specifically, these fish had a propensity to drift in the current or rest against the back of the chamber using the caudal fin, rather than swim against the current and flow of the water, even when the current flow was increased further to encourage the fish to swim. This was a behaviour the fish adapted when they spent more than $10 \mathrm{~min}$ in the chamber at low velocities. In order to force swimming and overcome this behaviour, the direction of water flow was changed into the opposite direction and laminar flow separators with larger holes $(50 \mathrm{~mm})$ were used where fish felt less comfortable as their fins were able to pass into the holes. The remaining species showed similar behaviour to $O$. mossambicus and would swim unpredictably within the chamber and constantly touch or remain in position against the back of the chamber in order to regain position or avoid swimming. Once this behaviour pattern was noted to be commonplace, the individual was replaced with another fish to determine the $U_{\text {crit }}$.

Differences in swimming performance and swimming behaviour were established based on the overall response of the fish species. Swimming behaviour is associated with the swimming tactics adopted by the fish to survive (Peake, 2008). Swimming performance is related to water velocities wherein the fish can maintain position and orientation, as well as swimming endurance (Peake, 2008; Plaut, 2001). Tactics employed by fish to resist motion, such as resting against the back of the chamber, are not suitable to ensure survival in natural conditions or to navigate through a fishway (Bok et al., 2007). Enteromius trimaculatus have a significantly higher ability to tolerate increased water velocity flows when compared to the other species within this study, a feat which was achieved without employing swimming tactics as seen with O. mossambicus.

The results of this study can therefore be compared to international fish species prolonged swimming performance guidelines, attained using a respirometer to determine critical swimming speed, i.e., the speed a fish can maintain between $15 \mathrm{~s}$ and $200 \mathrm{~min}$. In the design of fishways the maximum burst swimming velocity of a species, which a fish can maintain for only $15 \mathrm{~s}$, must be considered to enable the fish to endure the water velocity in the fishway between resting pools. Ross (2015) proposed a water velocity criterion for fishway designs in South Africa for migratory fish in the Vaal and Sabie Rivers, and suggested that the maximum water velocity through a fishway V-slot should be less than $170-190 \mathrm{~cm} \cdot \mathrm{s}^{-1}$. Ross (2015) did, however, note that burst forced swimming response in a laboratory setting was notably less vigorous than swimming behaviours under natural conditions where fish were more motivated. Bok et al. (2007) and Ross (2015) found that fish automatically adopted vigorous migration behaviours when a higher flow rate was placed at the entrance channel to a fishway.

Therefore, the data represented within this study should be applied with caution to predict prolonged swimming speeds in a natural environment. Laboratory-bred fish are fed on artificial foods and have lower foraging and exercise demands when compared to wild-caught fish, which could be a limiting factor to this study. However, laboratory fish are not subjected to stressors such as temperature fluctuations, pollutants, predators, parasites, etc. Notwithstanding these potential limitations, the laboratorybased critical swimming speed data provide a quantitative dataset for the comparison of the swimming ability of selected indigenous South African fish species.

\section{CONCLUSIONS}

The swimming performance of fish species in an Afrotropic ecozone can be influenced by body size, since swimming performance of larger fish yields higher $U_{\text {crit }}$ values. Oxygen consumption increases as fish experience physiological strain; a lower mass would lead to higher energy expenditure as seen in P. philander. Critical swimming speed, in conjunction with metabolic demand, has proven useful in determining laboratory-based baseline data for prolonged swimming abilities of South African fish species. 


\section{ACKNOWLEDGEMENTS}

The authors wish to thank NWU aquarium for supplying the fish.

\section{COMPETING INTERESTS}

The authors declare no competing or financial interests.

\section{AUTHOR CONTRIBUTIONS}

The authors collectively designed the study, performed the measurements, analysed the data and drafted the manuscript.

\section{REFERENCES}

BARBIERI E (2007) Use of metabolism and swimming activity to evaluate the sub-lethal toxicity surfactant (LAS-C12) on Mugilplatanus. Braz. Arch. Biol. Technol. 50 (1) 101-112. http:// dx.doi.org/10.1590/S1516-89132007000100012

BELLWOOD DR and FISHER R (2001) Relative swimming speeds in reef fish larvae. Mar. Ecol. Prog. Ser. 211 299-303. http://dx.doi. org/10.3354/meps211299

BOK A, KOTZE P, HEATH R and ROSSOUW J (2007) Guidelines for the planning, design and operation of fishways in South Africa. WRC Report No. TT 287/07. Water Research Commission, Pretoria.

BUSHNELL PG, STEFFENSON JF and JOHANSEN K (1984) Oxygen consumption and swimming performance in hypoxia acclimated rainbow trout Salmo gairdneri. J. Exp. Biol. 113 225-235. http:// dx.doi.org/content/113/1/225.

CARBONARA P, ZUPA W and LEMBO G (2012) Swimming performance and energetic expenditure in Pagrus Pagrus Pagrus (Linnaeus, 1958). Biol. Mar. Mediterr. 19 (1) 152-153. http://www. sibm.it/PDF\%20ATTI/PDF\%20CAMEROTA/Pagine\%20152-153.pdf

CASTRO-SANTOS T (2005) Optimal swim speeds for traversing velocity barriers: an analysis of volitional high-speed swimming behavior of migratory fishes. J. Exp. Biol. 208 (3) 421-432. http:// dx.doi.org/10.1242/jeb.01380.

DE PEYSTER A and LONG WF (1993) Fathead minnow optomotor response as a behavioral endpoint in aquatic toxicity testing. Bull. Environ. Contam. Toxicol. 51 (1) 88-95. https://doi.org/10.1007/ BF00201005

FISHER R and WILSON SK (2004) Maximum sustainable swimming speeds of late-stage larvae of nine species of reef fishes. J. Exp. Mar. Biol. Ecol. 312 171-186. https://doi.org/10.1016/j.jembe.2004.06.009

FISHER R and HOGAN JD (2007) Morphological predictors of swimming speed: a case study of pre-settlement juvenile coral reef fishes. J. Exp. Biol. 210 2436-2443. https://doi.org/10.1242/ jeb.004275

FUIMAN LA and WEBB PW (1988) Ontogeny of routine swimming activity and performance in zebrafish (Teleostei: Cyprinidae). Anim. Behav. 36 250-261. https://doi.org/10.1016/ S0003-3472(88)80268-9

GARCIA DE LEANIZ C (2008) Weir removal in salmonid streams: implications, challenges and practicalities. Hydrobiologia 609 83-96. https://doi.org/10.1007/s10750-008-9397-x

GOTANDA KM, REARDON EE, MURPHY SMC and CHAPMAN LJ (2012) Critical swim speed and fast-start response in the African cichlid Pseudocrenilabrus multicolour victoriae: convergent performance in divergent oxygen regimes. Can. J. Zool. $90545-$ 554. https://doi.org/10.1139/z2012-019

KLEYNHANS CJ (2003) National Aquatic Ecosystem Biomonitoring Programme: Report on a National Workshop on the use of Fish in Aquatic System Health Assessment. NAEBP Report Series No. 16.
Institute for Water Quality Studies, Department of Water Affairs and Forestry, Pretoria.

OHLBERGER J, STAAKS GBO and HOLKER F (2007) Effects of temperature, swimming speed and body mass on standard and active metabolic rate in vendace (Coregonus albular). J. Comp. Physiol. B 177 905-916. https://doi.org/10.1007/s00360-007-0189-9

OJANGUREN, AF and BRANA F (2003) Effects of size and morphology on swimming performance in juvenile brown trout (Salma trutta L.). Ecol. Freshwater Fish 12 241-246. https://doi. org/10.1046/j.1600-0633.2003.00016.x

PEAKE SJ (2008) Swimming performance and behaviour of fish species endemic to Newfoundland and Labrador: A literature review for the purpose of establishing design and water velocity criteria for fishways and culverts. Can. Manuscr. Rep. Fish. Aquat. Sci. 2843. Fisheries and Oceans Canada, St Johns NL. URL: http:// publications.gc.ca/collections/collection_2009/mpo-dfo/Fs97-42843E.pdf (Accessed 20 May 2018).

PLAUT I (2001) Critical swimming speed: its ecological relevance. Comp. Biochem. Physiol. A 131 (1) 41-50. https://doi.org/10.1016/ S1095-6433(01)00462-7

PLAUT I (2000) Effects of fin size on swimming performance, behavior and routine activity of Zebrafish Danio rerio. J. Exp. Biol. 203 813-820. http://jeb.biologists.org/content/203/4/813

PLAUT I and GORDON MS (1994) Swimming metabolism of wildtype and cloned Zebrafish Brachydanio rerio. J. Exp. Biol. 194 (1) 209-223. http://jeb.biologists.org/content/194/1/209

PON LB (2008) The role of fish physiology, behaviour, and water discharge on the attraction and passage of adult sockeye salmon (Onchorhynchus nerka) at the Seton River Dam Fishway, British Columbia. Unpublished MSc Thesis, University of British Columbia, Canada.

ROSS MJ (2015) Determining the biological requirements of selected important migratory fish species to aid in the design of fishways in South Africa. PhD thesis, University of Johannesburg.

SANTOS HA, POMPEU PS, VICENTINI GS and MARTINEZ CB (2007) Swimming performance of freshwater neotropical fish: Pimelodus maculatus Lacepede, 1803. Braz. J. Biol. 68 (2) 433-439. https://doi.org/10.1590/S1519-69842008000200029

SKELTON P (1993) A Complete Guide to the Freshwater Fishes of Southern Africa. Southern Book Publishers, Halfway House, South Africa.

SKELTON P (2001) A Complete Guide to the Freshwater Fishes of Southern Africa (2 ${ }^{\text {nd }}$ edn). Struik Publishers, Cape Town.

SMITH T and SHARMAN P (2013) Weirs, dams and other structures: Their effects on wild brown trout - WTT information paper. URL: http://www.wildtrout.org/sites/default/files/library/ Obstructions\%20information\%20paper\%2020082013.pdf (Accessed 8 August 2015).

SVENDSEN M B S, BUSHNELL PG and STEFFENSEN JF (2016) Design and setup of intermittent-flow respirometry system for aquatic organisms. J. Fish Biol. 88 26-50. https://doi.org/10.1111/ jfb.12797

TIERNEY, KB (2011) Swimming performance assessment in fishes. J. Visual Exp. 51 2572. https://doi.org/10.3791/2572

TUDORACHE C, VIAENE P, BLUST R, VEREECKEN H and DE BOEK G (2008) A comparison of swimming capacity and energy use in seven European freshwater fish species. Ecol. Freshwater Fish 17 (1) 284-291.

US DOE (United States Department of Energy) (2012) Research Priorities for Tropical Ecosystems Under Climate Change Workshop Report, DOE/SC-0153. United States Department of Energy, Office of Science. URL: www.science.energy.gov/ber/newsand-resources/ (Accessed 17 August 2015).

VIDELER JJ (1993) Fish Swimming. Chapman and Hall, London. https://doi.org/10.1007/978-94-011-1580-3 